\title{
Notes on the vocalizations of Japanese Paradise-flycatcher (Terpsiphone atrocaudata)
}

Peter Boesman

In the following we briefly analyze and compare voice of the three races of Japanese Paradiseflycatcher (Terpsiphone atrocaudata). We also try to quantify the extent of any vocal differences using the criteria proposed by Tobias et al. (2010), as a support for taxonomic review. We have made use of sound recordings available on-line from Xeno Canto (XC).

Comparison of song with some examples on sonograms:

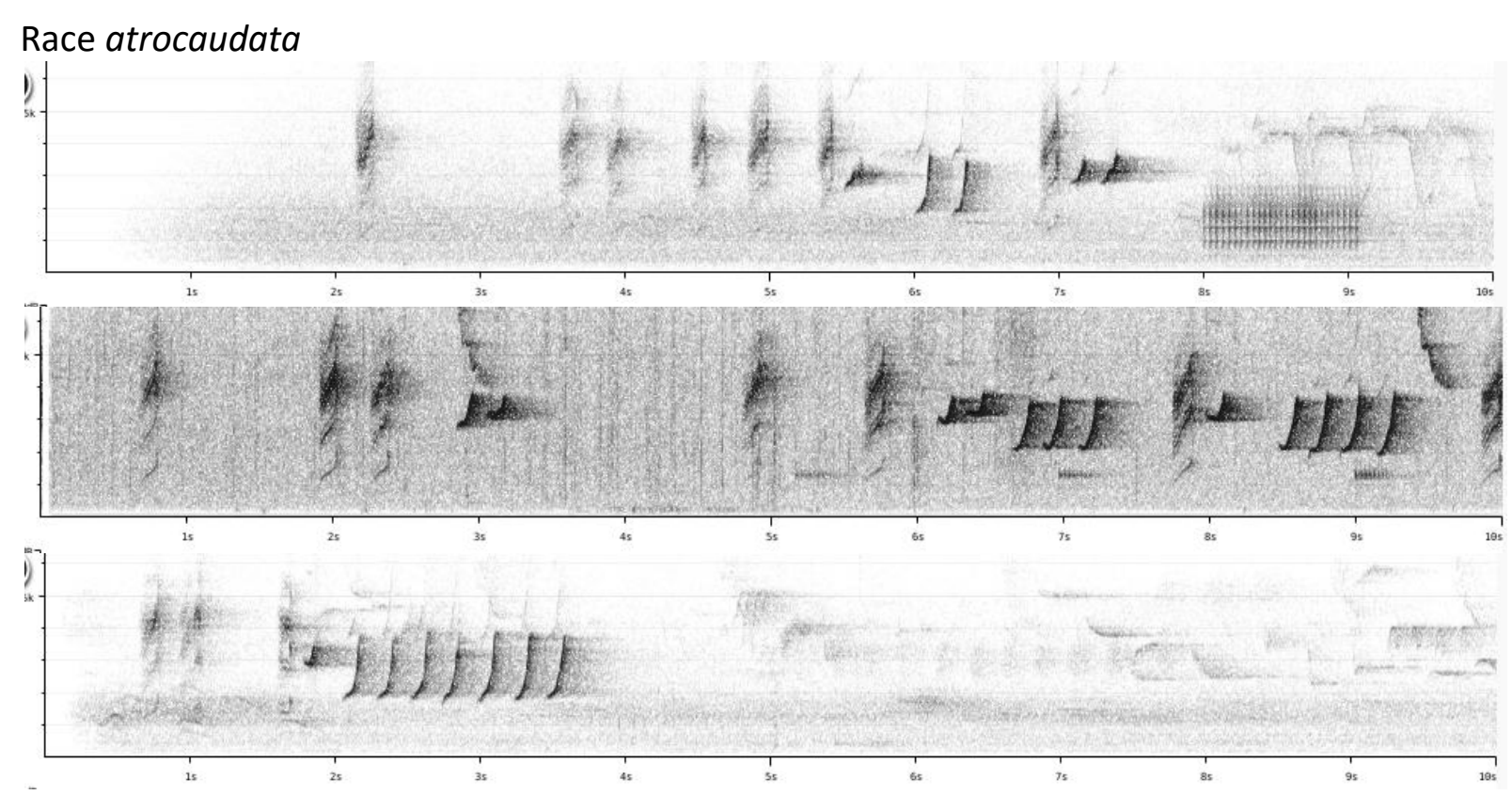

Race illex
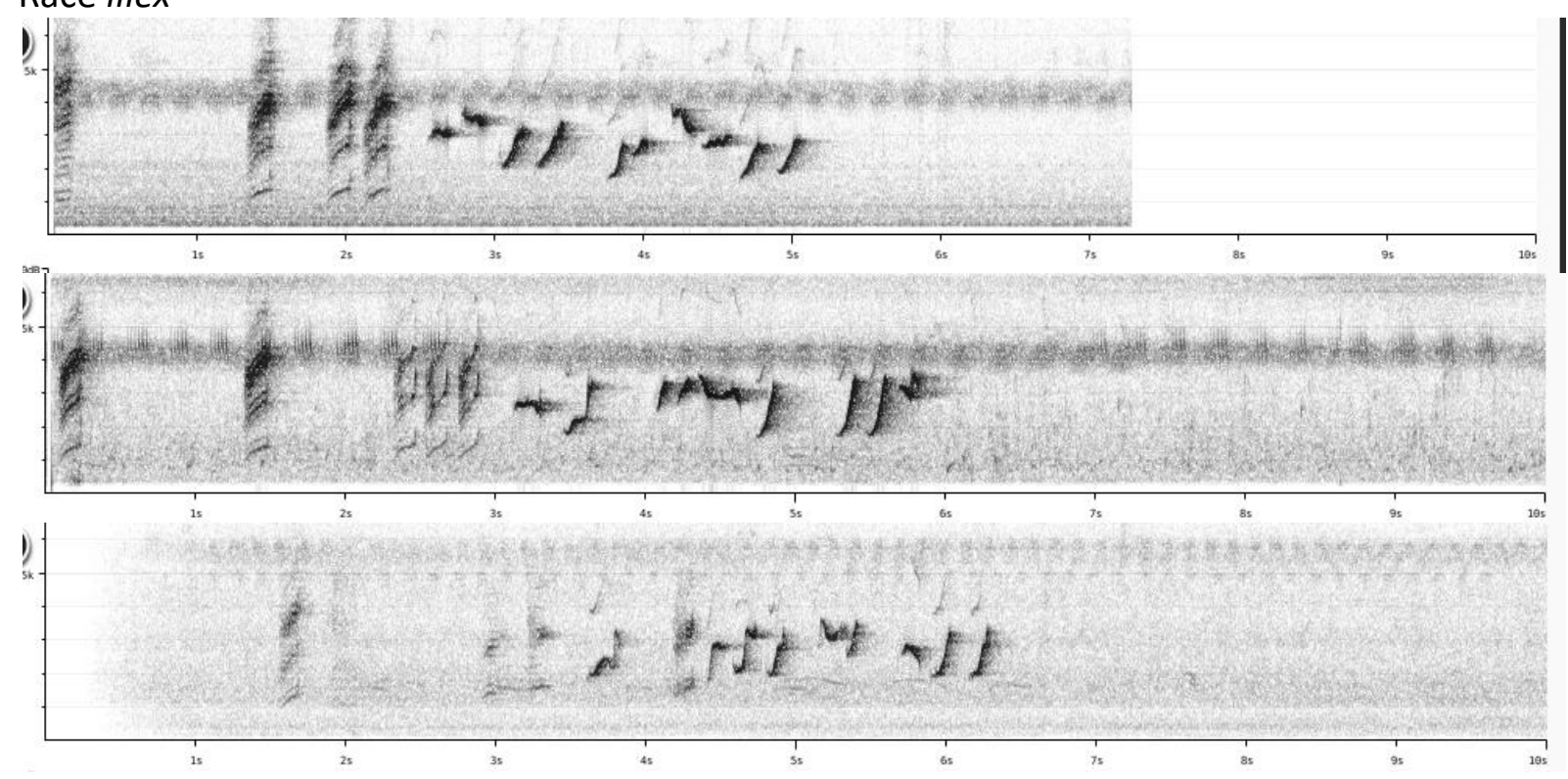

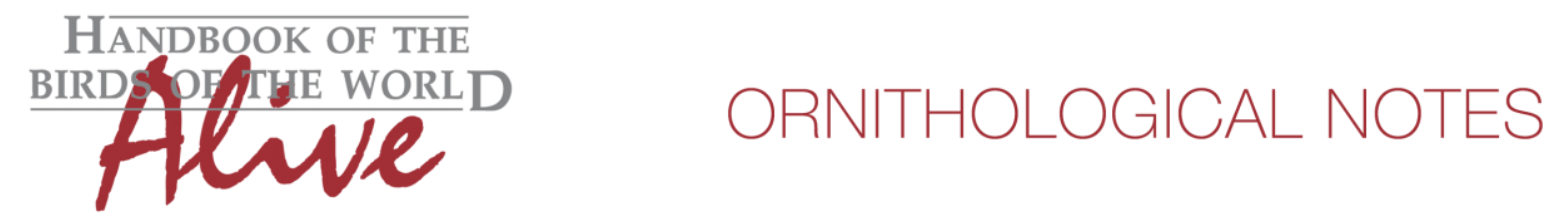

Race periophthalmica( $n=2$ !)

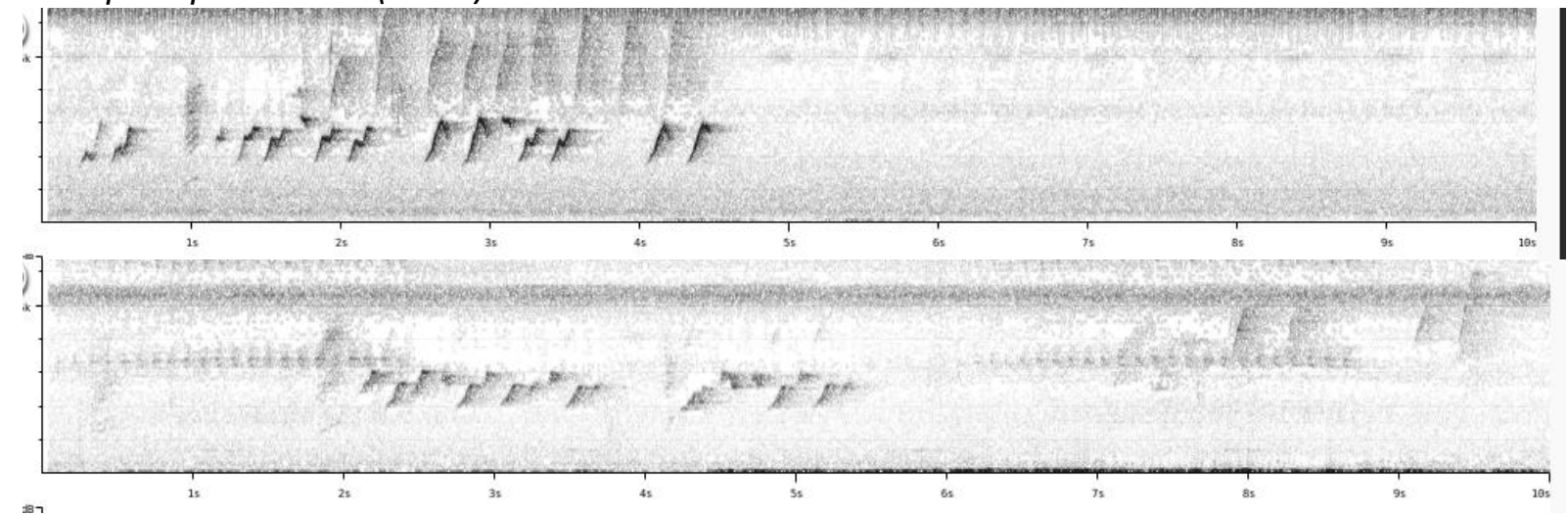

Song in all races is structurally similar: a series of different melodious whistles, often preceded by nasal raspy notes (the typical call notes). There are however clear differences among races:

periophthalmica lacks the upslurred whistles of both other races, its whistles similar to some of illex, which however also has upslurred whistles shared with atrocaudata.

atrocaudata has the smallest vocabulary with only a few different whistles, all simple in shape and upslurred, and there are apparently more (compared to illex) repeats of this upslurred whistle which covers a large frequency range.

There seems thus to be a gradual change between the 3 races, from many upslurs (atrocaudata), to a few with more other notes (illex), to only other notes (periophthalmica). Within each race there is however no obvious gradual change (e.g. the above examples of illex are taken from Amami, Okinawa and Ishigaki respectively, a distance from NE to SW of $c$ $700 \mathrm{~km})$.

The quantified vocal differences between atrocaudata and illex are thus mainly a different song vocabulary with e.g. lower number of repeated notes in illex (estimated score 2), and periophthalmlica having only notes with lower frequency range (absence of upslurs) (with some caution due to small sample size for this taxon !)(estimated score 2-3).

This note was finalized on 22nd January 2016, using sound recordings available on-line at that moment. We would like to thank in particular the sound recordists who placed their recordings for this species on XC: Peter Boesman, Chie-Jen Ko, Frank Lambert and Anon Torimi.

\section{References}

Tobias, J.A., Seddon, N., Spottiswoode, C.N., Pilgrim, J.D., Fishpool, L.D.C. \& Collar, N.J. (2010). Quantitative criteria for species delimitation. Ibis 152(4): 724-746. 


\section{Recommended citation}

Boesman, P. (2016). Notes on the vocalizations of Japanese Paradise-flycatcher (Terpsiphone atrocaudata). HBW Alive Ornithological Note 199. In: Handbook of the Birds of the World Alive. Lynx Edicions, Barcelona. (retrieved from http://www.hbw.com/node/932144 on 30 August 2016). 